\title{
Facilitation of Corticostriatal Transmission following Pharmacological Inhibition of Striatal Phosphodiesterase 10A: Role of Nitric Oxide-Soluble Guanylyl Cyclase-cGMP Signaling Pathways
}

\author{
Fernando E. Padovan-Neto, ${ }^{1}$ Stephen Sammut, ${ }^{1}$ Shreaya Chakroborty, ${ }^{1}$ Alexander M. Dec, ${ }^{1}$ Sarah Threlfell, ${ }^{1}$ \\ Peter W. Campbell, ${ }^{1}$ Vishnu Mudrakola, ${ }^{1}$ John F. Harms, ${ }^{2}$ Christopher J. Schmidt, ${ }^{2}$ and Anthony R. West ${ }^{1}$ \\ ${ }^{1}$ Department of Neuroscience, Rosalind Franklin University of Medicine and Science, North Chicago, Illinois 60064, and ${ }^{2}$ Pfizer Global Research and \\ Development, Groton, Connecticut 06340
}

\begin{abstract}
The striatum contains a rich variety of cyclic nucleotide phosphodiesterases (PDEs), which play a critical role in the regulation of cAMP and cGMP signaling. The dual-substrate enzyme PDE10A is the most highly expressed PDE in striatal medium-sized spiny neurons (MSNs) with low micromolar affinity for both cyclic nucleotides. Previously, we have shown that systemic and local administration of the selective PDE10A inhibitor TP-10 potently increased the responsiveness of MSNs to cortical stimulation. However, the signaling mechanisms underlying PDE10A inhibitor-induced changes in corticostriatal transmission are only partially understood. The current studies assessed the respective roles of cAMP and cGMP in the above effects using soluble guanylyl cyclase (sGC) or adenylate cyclase (AC) specific inhibitors. Cortically evoked spike activity was monitored in urethane-anesthetized rats using in vivo extracellular recordings performed proximal to a microdialysis probe during local infusion of vehicle, the selective SGC inhibitor ODQ, or the selective AC inhibitor SQ 22536. Systemic administration of TP-10 $(3.2 \mathrm{mg} / \mathrm{kg})$ robustly increased cortically evoked spike activity in a manner that was blocked following intrastriatal infusion of $\mathrm{ODQ}(50 \mu \mathrm{M})$. The effects of TP-10 on evoked activity were due to accumulation of cGMP, rather than cAMP, as the AC inhibitor SQ was without effect. Consistent with these observations, studies in neuronal NO synthase (nNOS) knock-out (KO) mice confirmed that PDE10A operates downstream of nNOS to limit cGMP production and excitatory corticostriatal transmission. Thus, stimulation of PDE10A acts to attenuate corticostriatal transmission in a manner largely dependent on effects directed at the NO-sGC-cGMP signaling cascade.
\end{abstract}

Key words: cGMP; medium-sized spiny neuron; nitric oxide; nitric oxide synthase; phosphodiesterase 10A; soluble guanylyl cyclase

\section{Introduction}

Cyclic nucleotides are second messengers involved in the modulation of synaptic transmission, homeostatic mechanisms, and gene expression (Greengard, 2001). Striatal medium-sized spiny neurons (MSNs) contain high levels of key enzymes involved in the synthesis and metabolism of cAMP and cGMP, including

Received March 27, 2014; revised Feb. 14, 2015; accepted March 4, 2015.

Author contributions: C.J.S. and A.R.W. designed research; F.E.P.-N., S.S., A.M.D., S.T., P.W.C., V.M., J.F.H., and A.R.W. performed research; F.E.P.-N., S.S., S.C., J.F.H., C.J.S., and A.R.W. analyzed data; F.E.P.-N., C.J.S., and A.R.W. wrote the paper.

This work was supported by Pfizer Inc. and United States Public Health Grants NS047452 and NS047452-05S2 to A.R.W. We thank Dr. Kuei Y. Tseng for valuable comments regarding the manuscript.

The authors declare no competing financial interests.

Correspondence should be addressed to Dr. Anthony R. West, Department of Neuroscience, Rosalind Franklin University of Medicine and Science, 3333 Green Bay Road, North Chicago, IL 60064. E-mail: Anthony.West@rosalindfranklin.edu.

S. Sammut's present address: Department of Psychology, Sociology, and Social Work, Franciscan University of Steubenville, 1235 University Boulevard, Steubenville, $\mathrm{OH} 43952$.

S. Threlfell's present address: University Department of Physiology, Anatomy and Genetics, Sherrington Building, Parks Road, 0xford, 0X13PT United Kingdom.

DOI:10.1523/JNEUROSCI.1238-14.2015

Copyright $\odot 2015$ the authors $\quad 0270-6474 / 15 / 355781-11 \$ 15.00 / 0$ adenylate cyclases (ACs), soluble guanylyl cyclases (sGCs), and cyclic nucleotide phosphodiesterases (PDEs) (Menniti et al., 2006). Activation of AC and sGC in the striatum is controlled by a variety of neurotransmitters (e.g., dopamine [DA], adenosine, glutamate) acting through G-protein coupled receptors and nitric oxide (NO) synthesis, respectively (Nishi et al., 2005; Threlfell and West, 2013). Metabolism of cAMP and cGMP occurs exclusively via activation of various PDEs (although efflux and extracellular metabolism may contribute significantly in some tissues) (Conti and Beavo, 2007; Hofer and Lefkimmiatis, 2007; Xie et al., 2011).

There are 21 human $3^{\prime}, 5^{\prime}$-PDE genes organized into 11 distinct families primarily based on sequence homology, kinetic properties, and substrate specificities (Bender and Beavo, 2006; Lugnier, 2006; Omori and Kotera, 2007). Splice variants within each family allow further diversity by introducing elements for subcellular localization. Beyond simply terminating cGMP or cAMP signaling, PDEs regulate the spatial and temporal compartmentalization of cyclic nucleotides, essentially sculpting the pattern of signaling by virtue of their differential regulation, localization, and enzymatic activity. In the rat, at least seven PDE 
families are expressed at moderate to high levels in the striatum (Menniti et al., 2006). Among these, the dual-substrate enzyme PDE10A (Fujishige et al., 1999, 2000; Loughney et al., 1999; Soderling et al., 1999) is relatively unique because it is expressed at high levels almost exclusively in striatal MSNs (Seeger et al., 2003; Coskran et al., 2006; Sano et al., 2008; Xie et al., 2011). Interestingly, inhibition of PDE10A via intrastriatal infusion of the selective inhibitor TP-10 increased the responsiveness of striatal MSNs to cortical input (Threlfell et al., 2009). Similar outcomes were obtained with systemic administration of TP-10. An increase in the responsiveness of striatonigral MSNs to antidromic activation during stimulation of the substantia nigra pars reticulata was also observed (Threlfell et al., 2009). These observations are consistent with previous studies showing that, under physiological conditions, drugs that augment cAMP or cGMP levels in MSNs (e.g., PDE inhibitors, NO generators, or cyclase activators) generally facilitate membrane excitability and corticostriatal transmission (Colwell and Levine, 1995; West et al., 2002; West and Grace, 2004; Tseng et al., 2011; Threlfell and West, 2013). However, the relative contributions of the AC-cAMP and NO-sGC-cGMP signaling pathways in mediating the effects of dual-substrate PDEs, such as PDE10A are not known.

Therefore, the current study used single-unit recordings to compare the effects of intrastriatal infusion of selective sGC and AC inhibitors on the facilitatory effects of PDE10A inhibition on corticostriatal transmission in the anesthetized rat. In addition, we compared the upstream elements of the signaling cascades regulated by PDE10A in neurochemical and electrophysiological studies using nNOS KO mice.

\section{Materials and Methods}

Drugs. Urethane, Cremophor EL, 2-hydroxypropyl- $\beta$-cyclodextrin, and 9-(tetrahydro-2-furanyl)-9H-purin-6-amine (SQ 22536) were purchased from Sigma Chemical. The selective sGC inhibitor $1 \mathrm{H}-[1,2,4]$ oxadiazolo-[4,3-a]quinoxalin-1-one (ODQ) (Garthwaite et al., 1995; Cechova and Pajewski, 2004) was purchased from Tocris Bioscience. 2-\{4-[-Pyridin-4-yl-1-(2,2,2-trifluoroethyl)-1H-pyrazol-3-yl]-phenoxymethyl\}-quinoline succinic acid (TP-10) (Schmidt et al., 2008) was synthesized at Pfizer Global Research and Development. All other reagents were of the highest grade commercially available.

In electrophysiological studies in rats combining systemic TP-10 administration and local reverse microdialysis of $\mathrm{sGC}$ and AC inhibitors, TP-10 (3.2 mg/kg s.c.) was dissolved in vehicle consisting of $10 \%$ Cremophor EL in physiological saline, and drug or vehicle was injected 10 min before recording. aCSF, ODQ $(50 \mu \mathrm{M})$, or SQ $22536(100 \mu \mathrm{M})$ was intrastriatally infused via reverse dialysis for at least $20 \mathrm{~min}$ before recording striatal neuron activity. The concentration of drug in the tissue immediately adjacent to the probe is estimated to be $\sim 10 \%$ of the concentration in the perfusion fluid (West and Galloway, 1997). Furthermore, the diffusion of drug into the extracellular space and brain parenchyma is expected to result in substantially lower concentrations at the soma of the neuron being recorded. In electrophysiological studies in mice, TP-10 (3.2 mg/kg s.c.) was dissolved in vehicle consisting of $40 \%$ 2 -hydroxypropyl- $\beta$-cyclodextrin solution and administered systemically (s.c.) $\sim 10$ min after obtaining stable baseline recordings (within-subjects design). One hour after drug, additional cells were isolated and recorded (70-180 $\mathrm{min})$ as described below (between-subjects design). In neurochemical studies, TP-10 was dissolved in vehicle consisting of 2-hydroxypropyl- $\beta$-cyclodextrin solution (10\%) and administered (3.2 $\mathrm{mg} / \mathrm{kg}$, s.c.) $30 \mathrm{~min}$ before tissue harvesting (see below).

In vivo extracellular single-unit recordings: rat studies. Electrophysiological recordings were performed on 46 male Sprague Dawley (Harlan) rats weighing 240-390 g. Rats were housed two-per cage under conditions of constant temperature $\left(22^{\circ} \mathrm{C}\right)$ and maintained on a 12:12 h light/ dark cycle with food and water available ad libitum. All animal procedures were approved by the Rosalind Franklin University of Med- icine and Science Institutional Animal Care and Use Committee and adhere to the Guide for the Care and Use of Laboratory Animals published by the United States Public Health Service. Rats were anesthetized deeply with urethane $(1.5 \mathrm{~g} / \mathrm{kg}$ in physiological saline). Cortical and striatal local field potentials were monitored as previously described (Tseng et al., 2011) to confirm that all recordings were performed while the animal was in a deeply anesthetized state. Temperature was monitored using a rectal probe and maintained at $37^{\circ} \mathrm{C}$ using a heating pad $(\mathrm{Vl}-20 \mathrm{~F}$, Fintronics). To minimize pain or discomfort, a solution of lidocaine $\mathrm{HCl}$ (2\%) and epinephrine $(1: 100,000)$ (Henry Schein) was injected into the scalp (s.c.) in a volume of $\sim 0.3 \mathrm{ml}$ and allowed to diffuse for several minutes. An incision $(\sim 2-4 \mathrm{~cm})$ was then made in the scalp, and burr holes ( $\sim 2-3 \mathrm{~mm}$ in diameter) were drilled in the skull overlying the right hemisphere of the frontal cortex (coordinates: $3.0-4.0 \mathrm{~mm}$ anterior from bregma, 1.5-2.2 $\mathrm{mm}$ lateral from the midline) and dorsal striatum (coordinates: -0.5 to $2.0 \mathrm{~mm}$ anterior from bregma, $2.0-3.5 \mathrm{~mm}$ lateral from the midline). In a subset of studies, to enable antidromic stimulation of the substantia nigra pars reticulata $(\mathrm{SNr})$, an additional burr hole was made overlying the right hemisphere of the $\mathrm{SNr}$ (coordinates: $5 \mathrm{~mm}$ posterior from bregma, $2.5 \mathrm{~mm}$ lateral from the midline). Electrophysiological recordings were performed as previously described (Threlfell et al., 2009; Sammut et al., 2010; Tseng et al., 2011). Briefly, extracellular microelectrodes were lowered incrementally through the dorsocentral striatum while single-pulse electrical stimuli were delivered to the cortex to isolate responsive single units. Our laboratory and others have used this approach to mimic naturally occurring corticostriatal synaptic drive in the anesthetized preparation (Mallet et al., 2005; Ondracek et al., 2008; Threlfell et al., 2009; Sammut et al., 2010; Sharott et al., 2012). Because the low-frequency test pulses used in this approach simultaneously activate powerful convergent glutamatergic inputs to striatal MSNs, this cortical stimulation closely reproduces the natural glutamate-driven transition to the up state and action potential generation observed to occur spontaneously in MSNs in intracellular recording studies (e.g., West and Grace, 2004). Thus, the examination of drug and genotypeinduced changes in cortically evoked spike activity provides important insight into the mechanisms involved in controlling synaptically driven spike activity and striatal output. Local drug administration using reverse microdialysis was achieved using probes implanted into the dorsal striatum, and extracellular recordings were initiated $\sim 3 \mathrm{~h}$ after probe implantation (Threlfell et al., 2009). Electrodes were positioned to enter the brain surface $\sim 1 \mathrm{~mm}$ lateral to the probe and lowered at a $10^{\circ}$ angle. Orthodromic and antidromic stimulation protocols, histological assessment, and data analysis were performed as previously described (Threlfell et al., 2009). Antidromic activation was used as in previous studies by our laboratory (Threlfell et al., 2009; Sammut et al., 2010) and others (e.g., Mallet et al., 2005) to identify a subpopulation of recorded neurons as striatonigral (MSN) projection cells. All unidentified cells included in this study had electrophysiological properties that were indistinguishable from the identified striatonigral MSNs. Furthermore, striatal neurons exhibiting spike characteristics resembling cholinergic or nitrergic cells (tonic or regular firing at a rate of $\sim 1-4 \mathrm{~Hz}$ ) or fast-spiking interneurons (respond to low intensity cortical stimulation with a high-frequency train of short duration $(<0.9 \mathrm{~ms}$ ) action potentials) (Mallet et al., 2005; Sharott et al., 2012) (see Fig. 4C) were not included in the current dataset. The statistical significance of drug-induced effects on neuronal activity was determined using either a $\chi^{2}$ test or two-way ANOVA (Sigma Stat, Jandel). A Tukey post hoc test was used to determine which group(s) contributed to overall differences observed with ANOVA.

In vivo extracellular single-unit recordings: mouse studies. All mouse procedures were approved by the Rosalind Franklin University of Medicine and Science Institutional Animal Care and Use Committee as described above for the rat studies. Experiments were performed on 19 male C57BL/6J wild-type and nNOS KO mice (8-10 weeks old) purchased from The Jackson Laboratory. Mice were anesthetized deeply with urethane $(1.5 \mathrm{~g} / \mathrm{kg}$ in physiological saline) and placed in a stereotaxic mouse adaptor (Narishige) fitted to the stereotaxic instrument used in the rat studies. Bipolar stimulating electrodes were implanted unilaterally into the frontal cortex using a micromanipulator (coordinates from bregma: $2 \mathrm{~mm}$ anterior, $2 \mathrm{~mm}$ lateral, and $1.2 \mathrm{~mm}$ ventral; Paxinos 
and Franklin, 2012) (see Fig. 4A). Glass extracellular electrophysiological recording electrodes were implanted into the striatum ipsilateral to the cortical stimulating electrode (coordinates from bregma: $0.1-1.0 \mathrm{~mm}$ anterior, $1.8-2.0 \mathrm{~mm}$ lateral, $1.5-3.5 \mathrm{~mm}$ ventral). Stimulation currents were titrated to an intensity (range, 280-3000 $\mu \mathrm{A}$ ), which reliably evoked spike activity $\sim 50 \%$ of the time to enable comparisons of cortically evoked activity across genotype and drug treatment groups. Next, the spontaneous (no stimulation) activity of striatal neurons was recorded for $\sim 2-3 \mathrm{~min}$. MSNs were classified as "spontaneously active" if they fired $>1$ action potential in the first $120 \mathrm{~s}$ of the recording epoch. The response to cortical stimulation was then reaffirmed before searching for the next cell (Ondracek et al., 2008; Sammut et al., 2010). Histological outcomes and data were analyzed as described above in the rat studies.

Neurochemistry. All animal experiments were performed according to National Institutes of Health and Pfizer Institutional Animal Care and Use Committee guidelines. Neurochemical experiments were performed on 24 male C57BL/6J and nNOS wild-type and KO mice purchased from The Jackson Laboratory. Brain tissue measures of cGMP and cAMP accumulation following drug administration were performed as previously described using focused microwave fixation of brain tissue (Schmidt et al., 2008). Regions of interest were isolated and homogenized in $0.5 \mathrm{~N}$ $\mathrm{HCl}$ followed by centrifugation. Supernatant concentrations of cyclic nucleotides were measured using enzyme immunoassay kits (Cayman Chemical). Statistical analysis was performed with GraphPad Prism (version 6.03) using two-way ANOVA with post hoc comparisons using a Bonferroni correction with the criterion for significance set at $p<0.05$.

\section{Results}

\section{Stimulating and recording electrode placements}

In rat studies, all stimulating electrode tips were confirmed to lie in the frontal cortex between 3.2 and $4.2 \mathrm{~mm}$ anterior to bregma, $1.4-2.5 \mathrm{~mm}$ lateral from the midline, and $1.0-3.0 \mathrm{~mm}$ ventral to the brain surface (Paxinos and Watson, 1998). Identified placements for extracellular recording electrodes implanted into the striatum were verified to lie between $1.2 \mathrm{~mm}$ anterior and 0.26 $\mathrm{mm}$ posterior from bregma, $1.8-3.9 \mathrm{~mm}$ lateral from midline, and $3.7-5.6 \mathrm{~mm}$ ventral to the brain surface (Paxinos and Watson, 1998).

In mouse studies, all stimulating electrode tips were confirmed to lie in the frontal cortex between 0.97 and $2.09 \mathrm{~mm}$ anterior to bregma, $1.0-2.0 \mathrm{~mm}$ lateral from the midline, and $0.8-1.5 \mathrm{~mm}$ ventral to the brain surface (Paxinos and Franklin, 2012). Identified placements for extracellular recording electrodes implanted into the striatum were verified to lie between 0.13 and $1.09 \mathrm{~mm}$ anterior to bregma, $1.5-2.0 \mathrm{~mm}$ lateral from midline, and $1.5-3.0 \mathrm{~mm}$ ventral to the brain surface (Paxinos and Franklin, 2012) (see Fig. 4C).

\section{Role of cAMP and cGMP signaling in the facilitatory effects of PDE10A inhibition}

The ability of PDE10A inhibition to affect corticostriatal signaling does not address the issue of which cyclic nucleotide may be mediating this effect. To address this question directly, we examined whether inhibition of sGC or AC altered the excitatory effects of systemic TP-10 using reverse microdialysis of the inhibitors ODQ and SQ, respectively. A range of stimulation intensities was applied in counterbalanced order for stimulus intensity across cells (i.e., the trial order of 600,800 , and 1000 or 1000,800 , or $600 \mu \mathrm{A}$ and was alternated for each cell). Cells recorded from vehicle-treated animals exhibited an increase in mean \pm SEM spike probability and a trend toward a decrease in mean spike onset latency that was dependent on increasing cortical stimulation intensities (Fig. 1). Significant main effects of TP-10 administration on spike probability were observed across all three stimulation intensities $\left(F_{(1,124)}=36.843, p<0.001\right.$; two-way ANOVA and Tukey post hoc test). Furthermore, significant main effects of current intensity on spike probability were observed within each of the treatment groups $\left(F_{(2,124)}=11.787\right.$, $p<0.001$; two-way ANOVA and Tukey post hoc test). No significant interactions were observed between drug treatment and stimulation intensity $(p>0.05)$. Pairwise comparisons revealed that systemic TP-10 administration induced a robust increase in spike probability for each applied stimulation trial compared with vehicle-treated controls (Fig. $1 ; p<0.01, p<0.001$ ). Significant main effects of TP-10 administration on spike onset latency were also observed $\left(F_{(1,112)}=8.064, p<0.01\right.$; two-way ANOVA and Tukey post hoc test). No significant main effects of stimulation intensity or interactions between drug treatment and stimulation intensity on spike onset latency were observed $(p>0.05)$. Pairwise comparisons revealed that, at higher stimulus intensities $(800-1000 \mu \mathrm{A})$, a strong trend toward a decrease in onset latency was observed in MSNs recorded in TP-10 treated rats (Fig. $1 ; p=$ 0.071 at $800 \mu \mathrm{A}$ and $p=0.082$ at $1000 \mu \mathrm{A}$ ).

We next compared the effects of intrastriatal ODQ infusion on systemic vehicle and TP-10-mediated changes in cortically evoked spike activity (Fig. 2, left). Significant main effects of TP-10 administration and intrastriatal ODQ infusion on spike probability were observed across all three stimulation intensities $\left(F_{(3,241)}=20.247, p<0.001\right.$; two-way ANOVA and Tukey post hoc test). Significant main effects of current intensity were also observed within each of the treatment groups $\left(F_{(2,241)}=22.979\right.$, $p<0.001$; two-way ANOVA and Tukey post hoc test). No significant interactions were observed between drug treatment and stimulation intensity $(p>0.05)$. Pairwise comparisons revealed that intrastriatal infusion of the selective sGC inhibitor ODQ (50 $\mu \mathrm{M})$ did not affect cortically evoked spike activity when administered before vehicle ( $p>0.05)$. However, ODQ infusion attenuated the facilitatory effects of TP-10 on cortically evoked spike activity as significant differences were observed between TP10/vehicle- and TP-10/ODQ-treated groups (Fig. 2, left; $p<$ $0.05, p<0.001)$. No significant main effects of ODQ or TP10/ODQ treatment on spike onset latency were observed (Fig. 2, left; $p>0.05)$.

Last, we compared the effects of intrastriatal SQ 22536 infusion on systemic vehicle- and TP-10-mediated changes in cortically evoked spike activity (Fig. 2, right). Significant main effects of TP-10 and SQ 22536 coadministration on spike probability were observed across increasing current intensities $\left(F_{(2,181)}=\right.$ 18.553, $p<0.001$; two-way ANOVA and Tukey post hoc test). Furthermore, significant main effects of current intensity were observed across treatment groups $\left(F_{(2,181)}=15.064, p<0.001\right.$; two-way ANOVA and Tukey post hoc test). No significant interactions were observed between drug treatment and stimulation intensity $(p>0.05)$. Pairwise comparisons revealed that systemic TP-10 administered with local SQ 22536 induced a robust increase in spike probability that was similar to that observed with local vehicle/systemic TP-10 treatment and significantly different from vehicle/systemic vehicle-treated controls (Fig. 2, right; $p=$ $0.05, p<0.05, p<0.01)$. Significant main effects of TP-10/SQ 22536 treatment on spike onset latency were observed $\left(F_{(2,168)}=\right.$ 4.672, $p<0.05$; two-way ANOVA and Tukey post hoc test); however, pairwise comparisons were not significant (Fig. 2, right; $p>$ 0.05 ). The incidence of antidromically identified striatonigral MSNs was not different across treatment groups (Table $1 ; p>$ $0.05 ; \chi^{2}$ test). This observation is in contrast to our previous report that TP-10 administration increases the proportion of striatonigral MSNs responding to antidromic activation (Threlfell et al., 2009). However, a much smaller sample size was avail- 
A
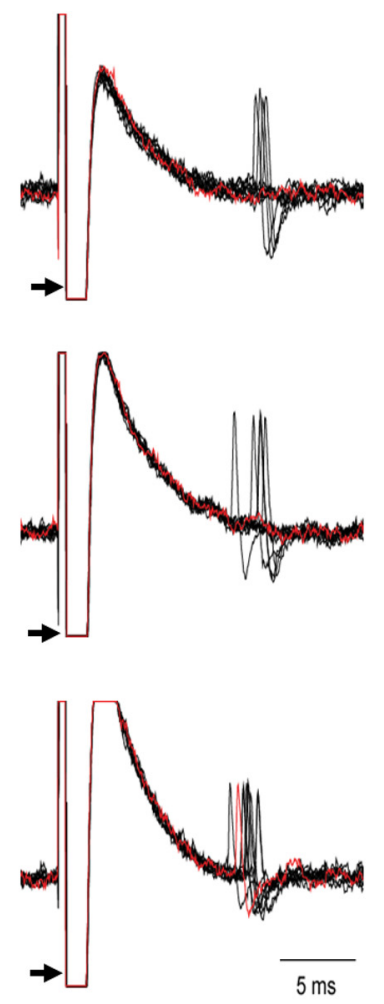

B
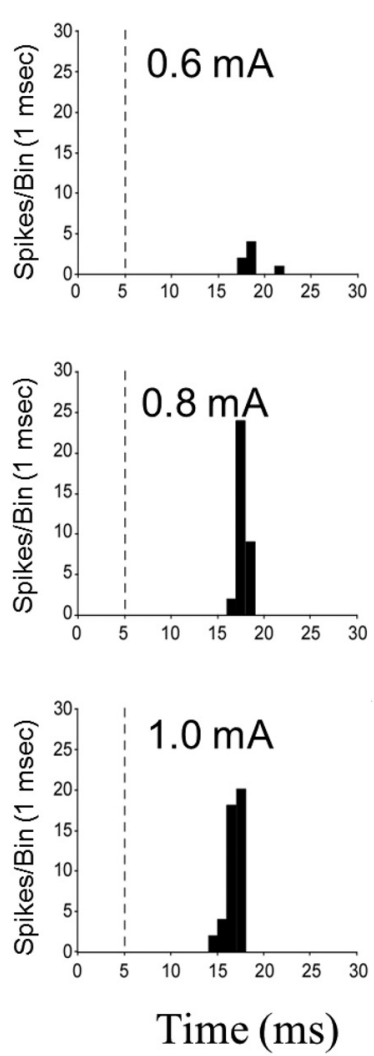

C

Systemic vehicle + local aCSF

Systemic TP-10 + local aCSF
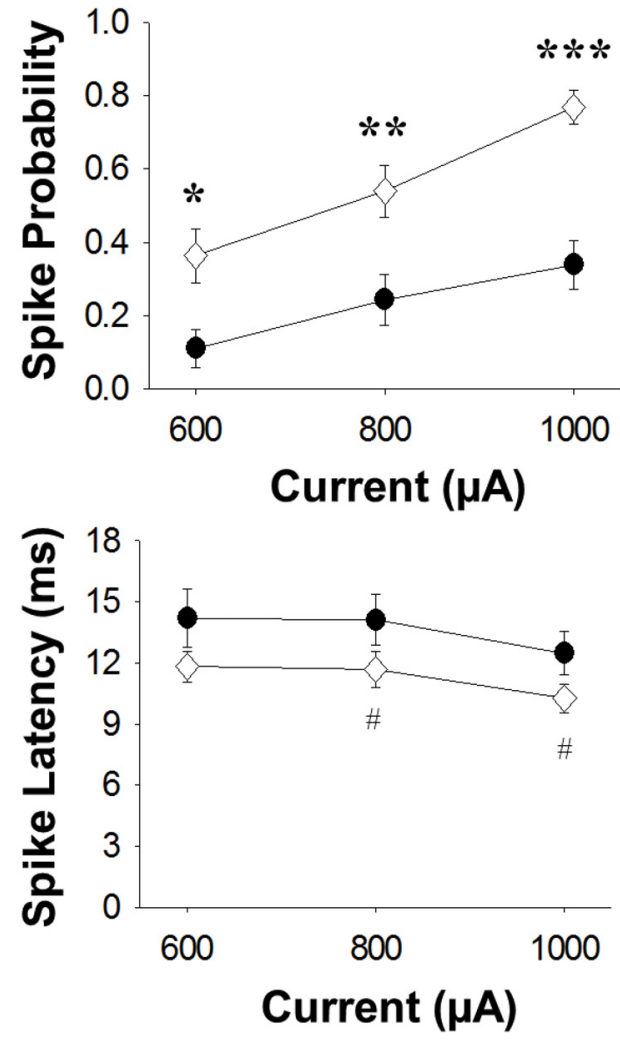

Figure 1. Effect of systemic PDE10A inhibition on cortically evoked activity recorded in vivo: extracellular recordings proximal to a microdialysis probe. $A$, Representative traces of cortically evoked spike activity of a single-unit recorded during intrastriatal aCSF infusion. In each case, 10 superimposed traces of cortically evoked spike responses from a single striatal neuron recorded under control conditions are shown for each stimulus intensity $(600,800$, and $1000 \mu \mathrm{A})$. Arrow indicates stimulus artifact. $\boldsymbol{B}$, Corresponding peristimulus time histograms showing the response of the same striatal neuron to cortex stimulation delivered over 50 stimulation trials. The probability of evoking a spike increases, whereas the spike onset latency typically decreases, with increasing stimulus intensities. C, Systemic administration of TP-10 significantly increased the mean \pm SEM probability of eliciting cortically evoked spike activity during aCSF infusion compared with vehicle-treated rats ${ }^{*} p<$ $0.05,{ }^{* *} p<0.01,{ }^{* * *} p<0.001$, two-way ANOVA, Tukey post hoc test). A trend toward a decrease in the mean \pm SEM onset latency of cortically evoked spike responses during aCSF infusion was observed following systemic treatment with TP-10 compared with vehicle-treated rats ( $\left.{ }^{*} p<0.09\right)$. Results are based on $n=20-26$ cells/8 or 9 rats per group.

able in the current study, and this, together with the implantation of the microdialysis probe, may have led to these negative findings. Last, consistent with our previous study (Threlfell et al., 2009), no significant differences in spontaneous firing activity were observed across treatment groups (Table $2 ; p>0.05$ ).

\section{nNOS is required to produce TP-10-mediated elevations in} striatal cGMP

Although sensitivity to inhibition of sGC implicates cGMP in the TP-10-mediated augmentation of corticostriatal activity, the results do not clarify the role of nNOS as an upstream mediator of the PDE10A inhibitor effects. Thus, we used nNOS KO animals to probe the enzymatic source of the cGMP pools being hydrolyzed by PDE10A. Age- and strain-matched wild-type (WT) and nNOS KO mice were treated with TP-10 (3.2 mg/kg, s.c.) $30 \mathrm{~min}$ before collection of striatal tissue samples for the determination of both cGMP and cAMP. Consistent with previous observations (Schmidt et al., 2008), TP-10 treatment resulted in significant increases in striatal cGMP and cAMP in WT animals (Fig. 3). For striatal cGMP, the effect of both treatment $\left(F_{(1,17)}=37.28, p<\right.$ 0.001; two-way ANOVA and Bonferroni post hoc test) and genotype $\left(F_{(1,17)}=110.4, p<0.001\right.$; two-way ANOVA and Bonferroni post hoc test) was significant with a significant interaction $\left(_{(1,17)}=30.74, p<0.001\right.$; two-way ANOVA and Bonferroni post hoc test). Post hoc analysis revealed a significant effect of TP-10 on cGMP accumulation in WT but not KO mice $(p<$ $0.05)$, as well as a significant difference between vehicletreated WT and nNOS KO mice $(p<0.05)$. For striatal cAMP, only the effect of treatment was significant, with TP-10 increasing cyclic nucleotide levels to the same extent in both WT and $\mathrm{KO}$ mice $\left(F_{(1,20)}=43.34, p<0.001\right.$; two-way ANOVA and Bonferroni post hoc test).

Impact of nNOS KO on spontaneous and cortically evoked spike activity

To determine whether decreased NO-cGMP tone impacts on corticostriatal transmission, we compared cortically evoked and spontaneous spike activity in striatal MSNs recorded from nNOS KO mice with age and strain-matched WT controls (Fig. 4B, C). We discovered in initial experiments that the normal current input/spike output relationship observed in MSNs recorded in rats and WT mice was disrupted in nNOS KO mice. Remarkably, current intensities ranging from 600 to $1000 \mu \mathrm{A}$ were rarely sufficient to evoke spike activity in nNOS KO mice (Fig. 4). Given that consistent spike activity could be evoked with current intensities $>1.0 \mathrm{~mA}$ in both WT and nNOS KO mice, we used an alternative stimulation paradigm in which spike probability is titrated to $\sim 50 \%$ by the experimenter and the current intensity is 
Systemic vehicle + local aCSF $\checkmark$ Systemic TP-10 + local aCSF

Systemic vehicle + local ODQ

A $\triangle$ Systemic TP-10 + local ODQ
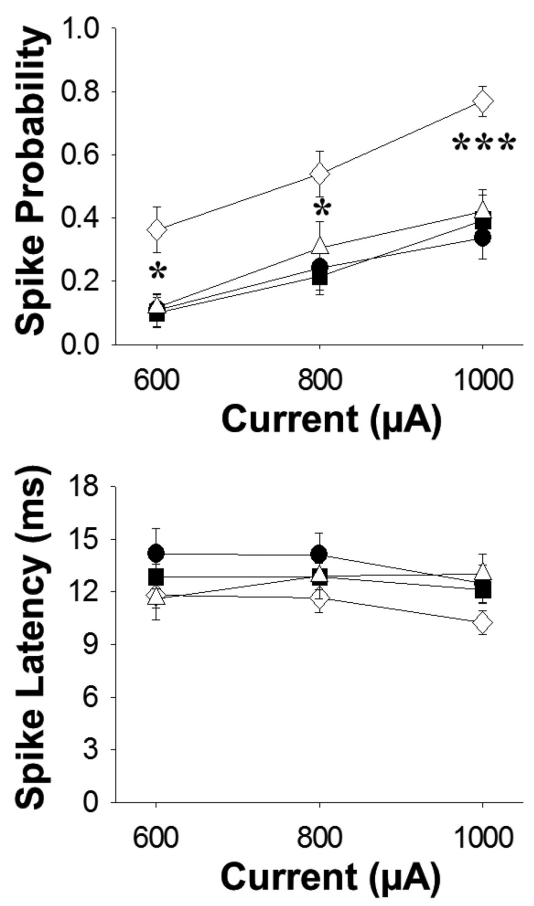

- Systemic vehicle + local aCSF $\diamond$ Systemic TP-10 + local aCSF $\nabla$ Systemic TP-10 + local SQ 22536

B
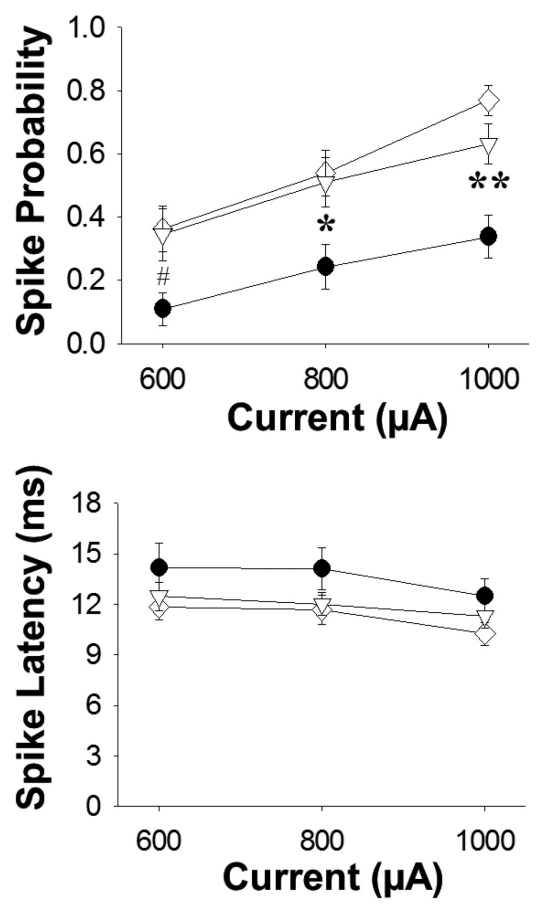

Figure 2. Effects of intrastriatal infusion of the selective SGC inhibitor ODQ and the selective AC inhibitor SQ 22536 on TP-10mediated facilitation of cortically evoked activity. All cells were recorded proximal to a microdialysis probe during aCSF, ODQ (50 $\mu \mathrm{M})$, or SQ $22536(100 \mu \mathrm{M})$ infusion. $A$, Top, Local ODQ infusion did not affect the mean \pm SEM probability of eliciting spike activity during cortical stimulation in vehicle-treated rats $(p>0.05$ ). However, the same pretreatment ( $\geq 20 \mathrm{~min}$ ) of ODQ blocked the TP-10-mediated increase in the mean \pm SEM probability of eliciting spike activity during cortical stimulation $\left({ }^{*} p<0.05,{ }^{* * *} p<\right.$ 0.001, two-way ANOVA, Tukey post hoc test compared with the TP-10/vehicle-treated group). Bottom, No significant changes in the mean \pm SEM spike onset latency were observed following ODQ infusion in vehicle- or TP-10-treated groups $(p>0.05)$. Results are based on $n=19-26$ cells/8-12 rats per group. $\boldsymbol{B}$, Top, Local SQ 22536 infusion did not affect the TP-10-mediated increase in the mean \pm SEM probability of eliciting spike activity during cortical stimulation $\left({ }^{\sharp} p=0.054,{ }^{*} p<0.05,{ }^{* *} p<0.01\right.$, two-way ANOVA, Tukey post hoc test). Bottom, No significant changes in the mean \pm SEM spike onset latency were observed following SQ 22536 infusion in vehicle- or TP-10-treated groups ( $p>0.05$ ). Results are based on $n=20-26$ cells $/ 8$ or 9 rats per group.

Table 1. Effects of drug manipulations on the relative proportion of striatal neurons exhibiting antidromic spikes in response to $\mathrm{SNr}_{\text {stimulation }}{ }^{a}$

\begin{tabular}{lll}
\hline Treatment & $\mathrm{SNr}^{+}$ & $\mathrm{SNr}^{-}$ \\
\hline Systemic vehicle + local aCSF & 3 & 10 \\
Systemic TP-10 + local aCSF & 4 & 13 \\
Systemic vehicle + local 0DQ & 4 & 14 \\
Systemic TP-10 + local 0DQ & 4 & 16 \\
Systemic TP-10 + local SQ 22536 & 4 & 15 \\
\hline
\end{tabular}

${ }^{a}$ There was no significant change in the number of $\mathrm{SNr}^{+}$cells recorded following local or systemic drug manipulations compared with vehicle administration ( $p>0.05 ; \chi^{2}$ test). Only a subset of all recorded striatal neurons were tested for antidromic responses.

recorded as the experimental variable. No significant difference in spike probability (titrated to $50 \%$ by the experimenter) was observed between WT and nNOS KO mice, indicating that currents were accurately titrated so as to allow for genotype comparisons across groups (Fig. $4 B, D ; p>0.05, t$ test). Interestingly, nNOS KO mice required significantly higher current amplitudes to evoke spike activity $\sim 50 \%$ of the time, suggesting that, in the intact striatum, NO-cGMP signaling plays a key role in mediating synaptic facilitation during stimulation of corticostriatal pathways (Fig. $4 E ; p<0.001, t$ test). It is also worth noting that with

this stimulation paradigm, relatively high current intensities were required to drive spike activity in a subpopulation of striatal MSNs recorded in WT controls (Fig. 4E). These observations indicate that a less excitable subpopulation of MSNs exists in the normal mouse striatum that would not normally be recruited to spike by the standard stimulation protocol used in the current rat studies and our previous reports (e.g., see Ondracek et al., 2008; Threlfell et al., 2009; Sammut et al., 2010). This may be due in part to suboptimal placement of cortical stimulating electrodes in relation to cortical innervation of this particular subpopulation of MSNs, lower intrinsic excitability of these cells, or a combination of these factors. No significant differences in spike latency (Fig. 4F; $p>0.05, t$ test) or SD of spike latency (data not shown; $p>0.05, t$ test) were observed between groups.

Interestingly, a significant difference was found between groups regarding the spontaneous activity (percentage of cells firing vs quiescent) of striatal MSNs that responded robustly to cortical stimulation. In these studies, $\sim 50 \%$ of striatal MSNs in the WT group were spontaneously active, compared with only $24 \%$ in the nNOS KO group (Fig. 4G; $p<0.05, \chi^{2}$ test), supporting pharmacological observations that NO signaling facilitates both corticostriatal transmission and the generation of spontaneous spike activity (West and Grace, 2004; Ondracek et al., 2008; Sammut et al., 2010). No significant differences in firing rate (Fig. $4 H ; p>$ $0.05, t$ test) or coefficient of variance of interspike interval (Fig. $4 I ; p>0.05, t$ test) were observed between groups.
nNOS is required to produce TP-10-mediated elevations in cortically evoked spike activity

Given that nNOS KO mice exhibit compromised cGMP synthesis and depressed cortically evoked and spontaneous MSN spike activity, we recorded additional cells in the same cohort of WT and nNOS KO mice to test whether upstream NO derived from nNOS is necessary for the facilitatory effects of TP-10 on cortically evoked firing. For these experiments, we first performed a within-subjects temporal analysis (individual cells were recorded as above at $10 \mathrm{~min}$ intervals starting at time 0 (predrug) and again every $10 \mathrm{~min}$ for $1 \mathrm{~h}$ after drug) to track the effects of TP-10 (3.2 $\mathrm{mg} / \mathrm{kg}$, s.c.) administration on cortically evoked responses in WT and nNOS KO mice. No significant difference in spike probability (titrated to $50 \%$ by the experimenter) was observed between WT and nNOS KO mice, indicating that currents were accurately titrated so as to allow for comparisons of drug effects across genotypes (Fig. $5 A ; p>0.05, t$ test). Consistent with the above studies, MSNs recorded in nNOS KO mice required significantly higher current amplitudes to evoke spike activity $~ 50 \%$ of the time (Fig. $5 B ; p<0.05, t$ test). Next, we compared the effects of TP-10-mediated changes in cortically evoked spike activity in 
Table 2. Effects of drug manipulations on the spontaneous firing activity of striatal neurons isolated during cortical stimulation ${ }^{a}$

\begin{tabular}{|c|c|c|c|c|}
\hline & Group & $\begin{array}{l}\text { Firing rate } \\
(\mathrm{Hz})\end{array}$ & $|S|$ (ms) & CV of $|S|$ \\
\hline \multirow{5}{*}{$\begin{array}{l}\text { Spontaneously active } \\
\text { cells }\end{array}$} & VV (8 cells) & $0.19 \pm 0.06$ & $10232.68 \pm 3277.43$ & $1.35 \pm 0.13$ \\
\hline & TP-V (8 cells) & $0.16 \pm 0.06$ & $12177.30 \pm 4244.10$ & $1.18 \pm 0.14$ \\
\hline & V-ODQ (8 cells) & $0.25 \pm 0.10$ & $17531.74 \pm 9320.03$ & $1.12 \pm 0.26$ \\
\hline & TP-ODQ (9 cells) & $0.13 \pm 0.04$ & $10988.07 \pm 3774.96$ & $0.95 \pm 0.16$ \\
\hline & TP-SQ (12 cells) & $0.21 \pm 0.07$ & $10485.38 \pm 4114.69$ & $1.06 \pm 0.15$ \\
\hline \multirow{5}{*}{$\begin{array}{l}\text { Spontaneously active } \\
\text { and quiescent } \\
\text { cells }\end{array}$} & VV (20 cells) & $0.07 \pm 0.03$ & $4093.07 \pm 1704.58$ & $0.49 \pm 0.16$ \\
\hline & TP-V (26 cells) & $0.05 \pm 0.02$ & $3746.86 \pm 1673.54$ & $0.36 \pm 0.12$ \\
\hline & V-ODQ (18 cells) & $0.11 \pm 0.05$ & $8250.23 \pm 4627.09$ & $0.59 \pm 0.18$ \\
\hline & TP-ODQ (20 cells) & $0.06 \pm 0.02$ & $4944.63 \pm 2067.08$ & $0.38 \pm 0.12$ \\
\hline & TP-SQ (20 cells) & $0.13 \pm 0.05$ & $6622.35 \pm 2820.62$ & $0.67 \pm 0.15$ \\
\hline
\end{tabular}

${ }^{a}$ There were no significant changes in spontaneous firing activity across treatment groups ( $p>0.05$; one-way ANOVA). Groups sizes for spontaneously active cells were $n=8-12$. Group sizes for all cells (active and quiescent) were $n=18-26$.

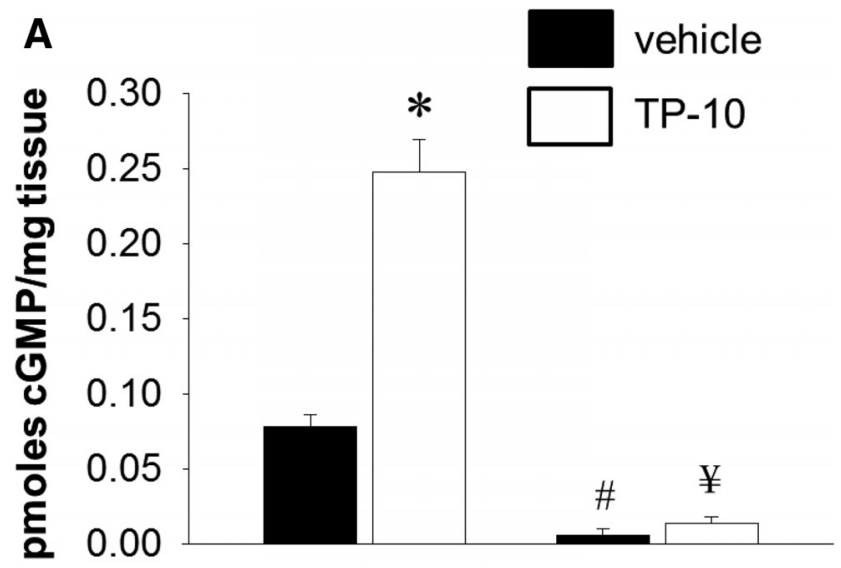

B

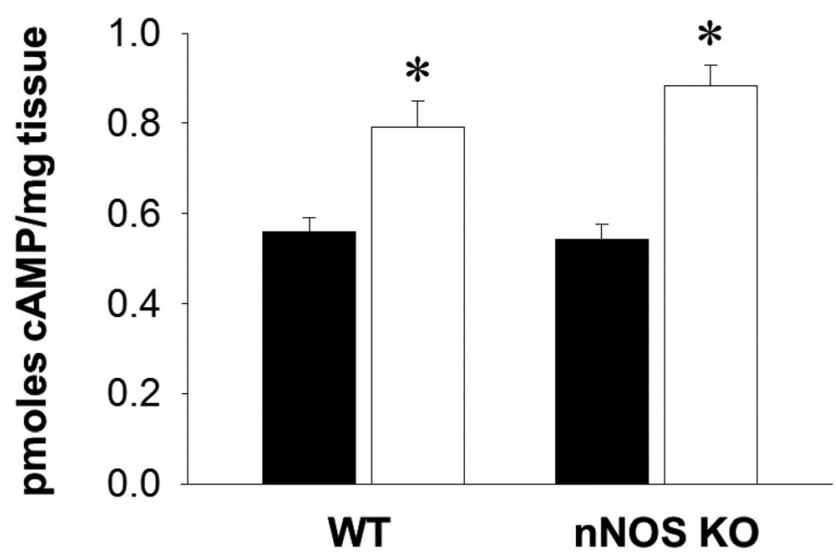

Figure 3. The effect of PDE10A inhibition with TP-10 on striatal concentrations of cGMP is absent in nNOS KO mice, whereas the elevation of CAMP is unaffected. C57BL/6J WT and nNOS KO mice were injected with vehicle or TP-10 (3.2 mg/kg, s.c.). Brain tissue measures of cGMP accumulation were performed $30 \mathrm{~min}$ after vehicle/drug injection (Schmidt et al., 2008). $A$, Systemic TP-10 administration induced a robust increase in cGMP levels in the striatum of WT mice. ${ }^{*} p<0.05$ (two-way ANOVA, Bonferroni post hoc test). Striatal concentrations of CGMP were significantly decreased in vehicle-treated nNOS KO animals compared with age-matched WT controls. ${ }^{\#} p<0.05$ (tw0-way ANOVA, Bonferroni post hoc test). Moreover, striatal cGMP levels were not elevated by TP-10 treatment in nNOS KO mice and were significantly reduced compared with TP-10 treated WT mice. ${ }^{*} p<0.05$ (two-way ANOVA, Bonferroni post hoc test). $\boldsymbol{B}$, TP-10 administration induced a robust increase in cAMP levels in the striatum of both WT and nNOS KO mice. ${ }^{*} p<0.05$ (two-way ANOVA, Bonferroni post hoc test). No influence of genotype was observed ( $p>0.05$ ). Results are based on $n=6$ mice per group.
WT and nNOS KO mice (Fig. 5C). Significant main effects of time after drug were observed on the current intensity required to evoke spike activity $50 \%$ of the time $\left(F_{(4,40)}=6.98, p<0.001\right.$; two-way repeated-measures ANOVA and Tukey post hoc test). Significant interactions were observed between time after drug and genotype $\left(F_{(1,40)}=2.61, p<0.05\right.$; two-way repeatedmeasures ANOVA and Tukey post hoc test). Pairwise comparisons revealed that TP-10 administration induced a facilitatory effect on cortically evoked spike activity in the WT group as significant reductions in current intensity required to evoke spike activity $50 \%$ of the time were observed $40-60 \mathrm{~min}$ after drug ( $p<0.05$ compared with 10-20 min measures). Conversely, TP-10 did not change the current intensity required to evoke spike activity $50 \%$ of the time in nNOS KO mice $(p>0.05)$, indicating that NO-derived from nNOS is necessary for the initial facilitatory effects of PDE10A inhibition on cortically evoked firing. No significant differences in the onset latency, SD of latency, or spontaneous firing activity were observed across groups $(p>$ 0.05; data not shown).

To further assess the role of nNOS in the above effects, we conducted a between-subjects analysis of cortically evoked and spontaneous activity in a separate subpopulation of striatal MSNs recorded in the same mice immediately after the within-subjects studies. These studies were performed $70-180 \mathrm{~min}$ after TP-10 administration. This time period was selected based on previous work showing that systemic TP-10 administration (dose used herein) produces a peak increase in tissue cGMP and cAMP 60 180 min after injection (Schmidt et al., 2008). No significant difference in spike probability (titrated to $50 \%$ by the experimenter) was observed between WT and nNOS KO mice, indicating that currents were accurately titrated across groups (Fig. $6 A, B ; p>0.05, t$ test). Comparisons of the effects of TP-10 administration across genotypes indicated that MSNs recorded in nNOS KO mice were less responsive to drug than WT controls (Fig. $6 C ; p<0.001, t$ test). Similar outcomes were apparent for measures of onset latency of cortically evoked spikes (Fig. $6 D ; p<$ $0.05, t$ test). No significant difference in the proportion of spontaneously firing to quiescent MSNs was found between genotypes after TP-10 administration (Fig. $6 E ; p>0.05 ; \chi^{2}$ test). TP-10 administration had a tendency to increase the firing rate of MSNs recorded in the WT striatum compared with nNOS KO mice; however, this effect did not reach significance (Fig. 6F; $p=0.0827 ; t$ test). TP-10 administration did not alter the coefficient of variance of the interspike interval of spontaneous spikes (Fig. 6G).

\section{Discussion}

The current study found that systemic TP-10 administration robustly increases the responsiveness of MSNs recorded in WT rats and mice to excitatory corticostriatal transmission driven by stimulation of the frontal cortex. These observations are consistent with our previous work, which showed that systemic and intrastriatal administration of TP-10 facilitated cortically evoked activity (Threlfell et al., 2009). Importantly, we now report that sGC inhibition, but not AC inhibition, blocks the facilitatory effects of TP-10. Further studies in nNOS KO mice revealed that TP-10-induced increases in cGMP levels and cortically evoked spike activity are dependent on intact NO transmission; thus, it is likely that PDE10A acts to filter asynchronous or weak cortical input to MSNs by specifically suppressing NO-sGCcGMP signaling. 
A
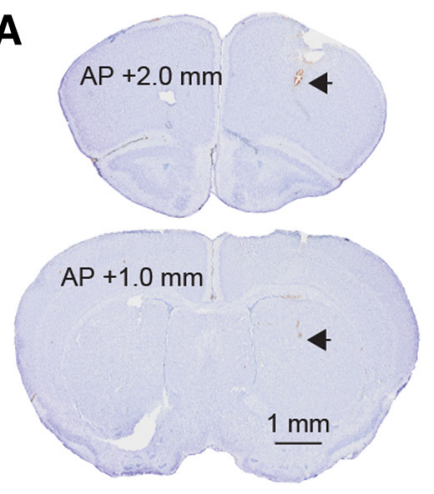

D

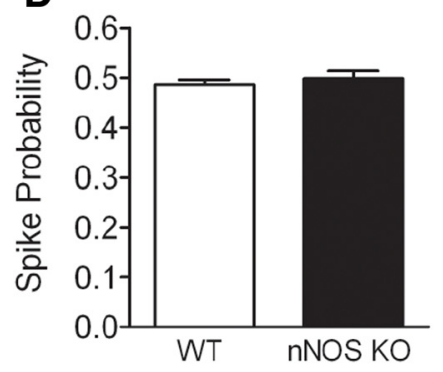

B
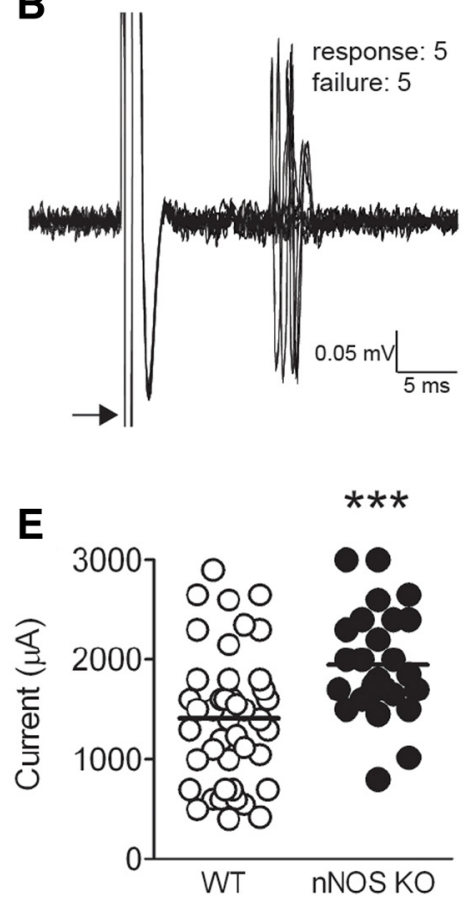

H

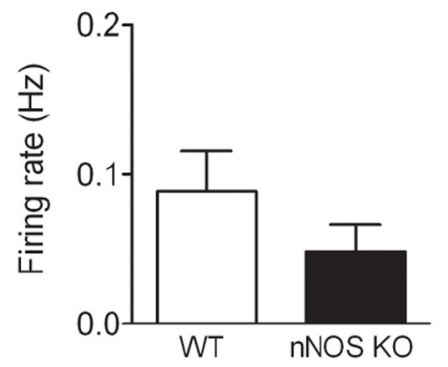

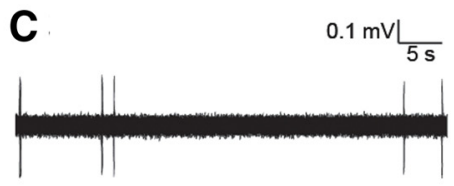

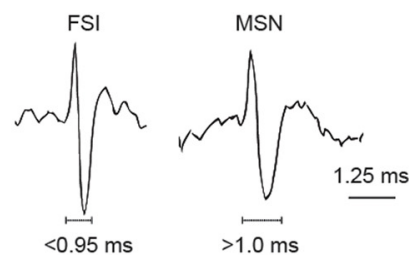

$\mathbf{F}$

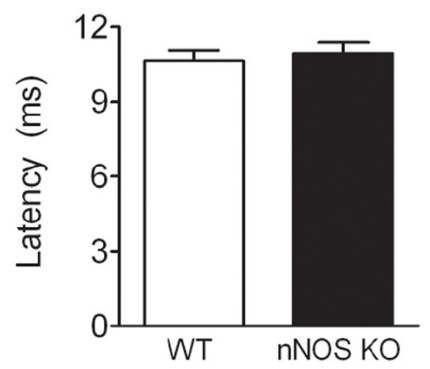

I

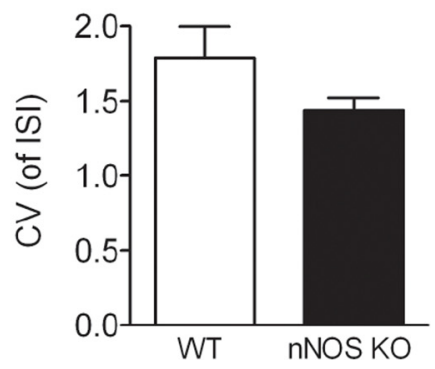

Figure 4. Decreased cortically evoked and spontaneous firing activity in MSNs recorded from nNOS KO mice. $A$, Representative electrode placements in frontal cortex and dorsal striatum of the mouse. Large black arrows indicate the termination sites of the stimulating electrode implanted in the cortex and the recording electrode implanted in striatum. $\boldsymbol{B}$, Representative traces of cortically evoked spike activity of a single-unit recorded in the mouse. Ten superimposed traces of cortically evoked spike responses from a single striatal MSN are shown. Arrow indicates stimulation artifact. C, Top, Representative record demonstrating spontaneous activity of an MSN that responded to cortical stimulation. Bottom, In addition to their irregular spiking pattern and stereotypical response to cortical stimulation, MSNs wereidentified by action potential duration ( $>1.0 \mathrm{~ms}$ ) as documented in previous studies (Mallet et al., 2005). Although not frequently encountered, fast spiking interneurons (FSIs) were distinguished from MSNs by their short-latency response to cortical stimulation, rapid firing pattern, and short duration action potential $(<0.95 \mathrm{~ms})$. FSIs were not included in this study. D, Spike probability was titrated to $\sim 50 \%$ by the experimenter, and no differences in the probability of responses evoked by cortical stimulation were observed between WT and nNOS KO mice, indicating that currents were titrated accurately across groups ( $p>$ $0.05 ; t$ test). $E$, Striatal MSNs recorded in nNOS KO mice showed decreased responsiveness to cortical stimulation. Thus, an increase in the current intensity required to elicit spike activity $\sim 50 \%$ of the time was observed in nNOS KO mice. ${ }^{* * *} p<0.001$ ( $t$ test). $\boldsymbol{F}$, No difference in the mean \pm SEM onset latency of cortically evoked spikes was observed in MSNs recorded in WT and nNOS KO mice ( $p>0.05 ; t$ test). D $-\boldsymbol{F}$, Data are derived from $n=43$ WT MSNs ( 9 mice) and $n=26 \mathrm{nNOS} \mathrm{KO} \mathrm{MSNs} \mathrm{(8} \mathrm{mice).} \mathrm{G,} \mathrm{Percentage} \mathrm{of} \mathrm{cells} \mathrm{that} \mathrm{responded} \mathrm{robustly} \mathrm{to} \mathrm{cortical} \mathrm{stimulation} \mathrm{that} \mathrm{were} \mathrm{firing} \mathrm{or} \mathrm{quiescent} \mathrm{in} \mathrm{WT} \mathrm{and} \mathrm{nNOS} \mathrm{mice.} \mathrm{The}$ number of cells that are quiescent or firing is indicated within the percentage bars. An overall decrease in the population of spontaneously firing MSNs recorded was observed in the striatum of nNOS KO mice compared with WT controls. ${ }^{*} p<0.05$ ( $\chi^{2}$ test). $\boldsymbol{H}, \boldsymbol{I}$, No difference in the mean \pm SEM firing rate or coefficient of variance (CV) of the interspike interval (ISI) of spontaneously firing striatal MSNs was observed across groups $(p>0.05 ;$ t test). Data are derived from $n=42$ WT and $n=25$ nNOS KO MSNs (9 mice per group).

\section{Modulation of striatal MSN spike activity by PDE10A regulation of NO-sGC-cGMP signaling}

PDE10A functions as a dual-substrate enzyme, acting to degrade both cGMP and cAMP (Bender and Beavo, 2006). Therefore, the effects observed following TP-10 administration may have been mediated by either or both of these cyclic nucleotides. Several studies published by our laboratory and others have shown that, under physiological conditions, drugs that elevate cAMP or cGMP concentrations in MSNs (e.g., PDE inhibitors, cyclase activators, NO generators in the case of cGMP) augment spontaneous and evoked corticostriatal transmission (Threlfell and West,
2013). Furthermore, studies using zaprinast or papaverine to inhibit PDEs, which selectively degrade cGMP, have shown that PDE inhibition robustly facilitates corticostriatal transmission (Threlfell and West, 2013). Thus, intracellular injection of zaprinast or papaverine increased the duration of spontaneous "up states" driven in the intact striatum by cortical activity and depolarized the resting membrane potential of striatal MSNs. Conversely, drugs that attenuate cyclic nucleotide synthesis or block protein kinase activity have opposite effects (Colwell and Levine, 1995; West and Grace, 2004; Tseng et al., 2007, 2011). 
The demonstration that ODQ blocked TP-10 mediated facilitation of cortically evoked spike activity, while SQ 22536 was without effect, strongly suggests that cGMP is primarily responsible for the observed effects of TP-10. Although intrastriatal infusion of ODQ alone at a concentration of $50 \mu \mathrm{M}$ did not alter cortically evoked activity, we have observed that higher doses of ODQ can suppress cortically evoked firing in a manner similar to that observed following systemic administration of this compound (Sammut et al., 2010). Furthermore, systemic ODQ administration attenuates cortically evoked postsynaptic potentials (PSPs) recorded in the striatum in a manner that is reversed by intrastriatal infusion of the cGMP analog 8-Br-cGMP (Tseng et al., 2011). Previous studies have also shown that intracellular application of ODQ suppresses spontaneous glutamate-driven depolarizing up states and firing activity evoked in MSNs by depolarizing current pulses (West and Grace, 2004). Importantly, both of these effects of ODQ were reversed by coapplication of cGMP. Together, these studies indicate that inhibition of cGMP metabolism induced by TP-10 leads to a cGMPmediated upregulation of corticostriatal transmission.

In addition to nNOS, cGMP tone is thought to be maintained in part in the striatum by other constitutively active enzymes, including endothelial NOS and particulate guanylyl cyclase (Threlfell and West, 2013). Thus, nNOS KO mice were used in a separate set of experiments to probe the role of nNOS as an upstream mediator of the PDE10A inhibitor effects on cGMP accumulation and cortically evoked firing. Consistent with previous observations (Schmidt et al., 2008), TP-10 administration resulted in significant increases in striatal tissue concentrations of both cGMP and cAMP in WT animals. Concentrations of cGMP were reduced to near undetectable levels in the striatum of vehicle-treated nNOS KO animals, whereas cAMP concentrations were comparable with WT controls. Moreover, although TP-10 treatment produced the expected increase in cAMP, it did not produce a significant increase in striatal cGMP in nNOS KO mice, indicating that nNOS operates upstream of $\mathrm{sGC}$ and the pool of cGMP mediating the effects of TP-10 on corticostriatal transmission. Consistent with this, the current electrophysiological studies in nNOS KO mice showed that loss of nNOS function is sufficient to block the initial excitatory effects of TP-10 on cortically evoked activity.

We also examined the impact of genetic deletion of nNOS on spontaneous and cortically evoked MSN activity. We found that nNOS KO mice were substantially less responsive to cortical drive compared with their WT counterparts. Recordings of basal activity revealed that the striatum of nNOS KO mice is exceptionally "quiet" as substantially fewer cells (24\%) exhibited spontaneously firing activity compared with WT controls (50\%). Together, these observations are highly consistent with a growing body of pharmacological studies indicating that tonic $\mathrm{NO}$ acts to facilitate spontaneous MSN firing and corticostriatal transmission in the intact striatum (West, 2010; West and Tseng, 2011; Threlfell and West, 2013). For example, we have reported that systemic administration of the nNOS inhibitor 7-nitroindazole potently inhibited the spontaneous firing activity of striatal neu-
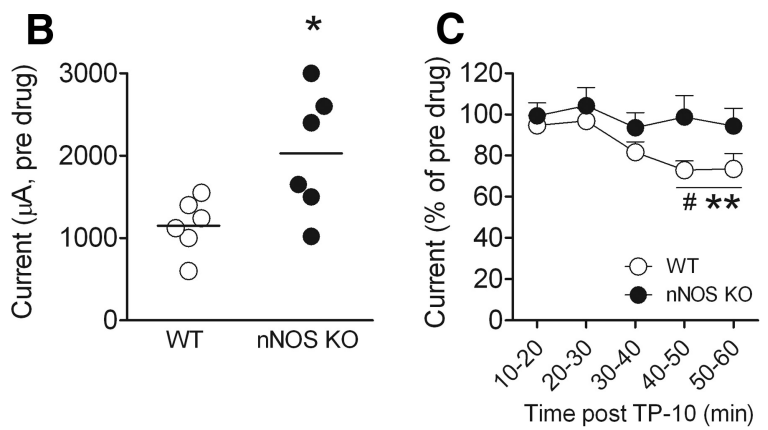

isolated during low-frequency cortical stimulation (Ondracek et al., 2008). Further studies using intracellular recordings in vivo showed that disruption of local $\mathrm{NO}$ signaling using intrastriatal application of 7-nitroindazole or the NO scavenger CPT-IO depressed glutamate-driven up states and evoked EPSPs, and decreased the responsiveness of identified MSNs to somatic injection of depolarizing current (West and Grace, 2004). The inhibitory effects of CPT-IO on neuronal activity were reversed by coapplication of cGMP analogs, indicating that, in the intact striatum, endogenous tonic NO-cGMP signaling increases the membrane excitability of MSNs and their responsiveness to excitatory glutamatergic transmission (West and Grace, 2004). In support of the above findings, recent studies combining electrochemical and electrophysiological approaches have shown that local infusion of the nonselective NOS inhibitor $\mathrm{N}^{\mathrm{G}}$-nitro-Larginine methyl ester attenuates both glutamate and aspartate release, as well as PSPs recorded in the dorsolateral nucleus accumbens during electrical stimulation of the thalamus (Kraus et al., 2014). Additionally, microiontophoresis of the NO generator sodium nitroprusside was shown to increase the spontaneous firing rate of $>75 \%$ of recorded striatal neurons and to facilitate glutamate-evoked firing in a subpopulation of putative MSNs (Liu et al., 2005). These investigators also reported that microiontophoresis of $\mathrm{N}^{\mathrm{G}}$-nitro-L-arginine methyl ester produced opposite effects on glutamate-evoked firing (Liu et al., 2005). Furthermore, we have shown that burst stimulation of frontal cortical afferents in the intact animal activates a powerful feedforward excitation of MSN activity, which is mediated by phasic NO signaling and sensitive to nNOS inhibitor administration (Ondracek et al., 2008).

Together, the current findings in nNOS KO mice and the studies discussed above indicate that in the intact striatum NOsGC-cGMP signaling primarily acts to facilitate glutamate transmission and that this pathway is strongly downregulated by activation of PDE10A. While the mechanisms downstream of cGMP are not presently known, activation of DA and cAMP regulated phosphoprotein MW $32 \mathrm{kDa}$ (DARPP-32) is thought to play a critical role in mediating many of the neuromodulatory effects of NO on local striatal glutamatergic transmission (Greengard, 2001). The PKG-mediated phosphorylation of DARPP-32 

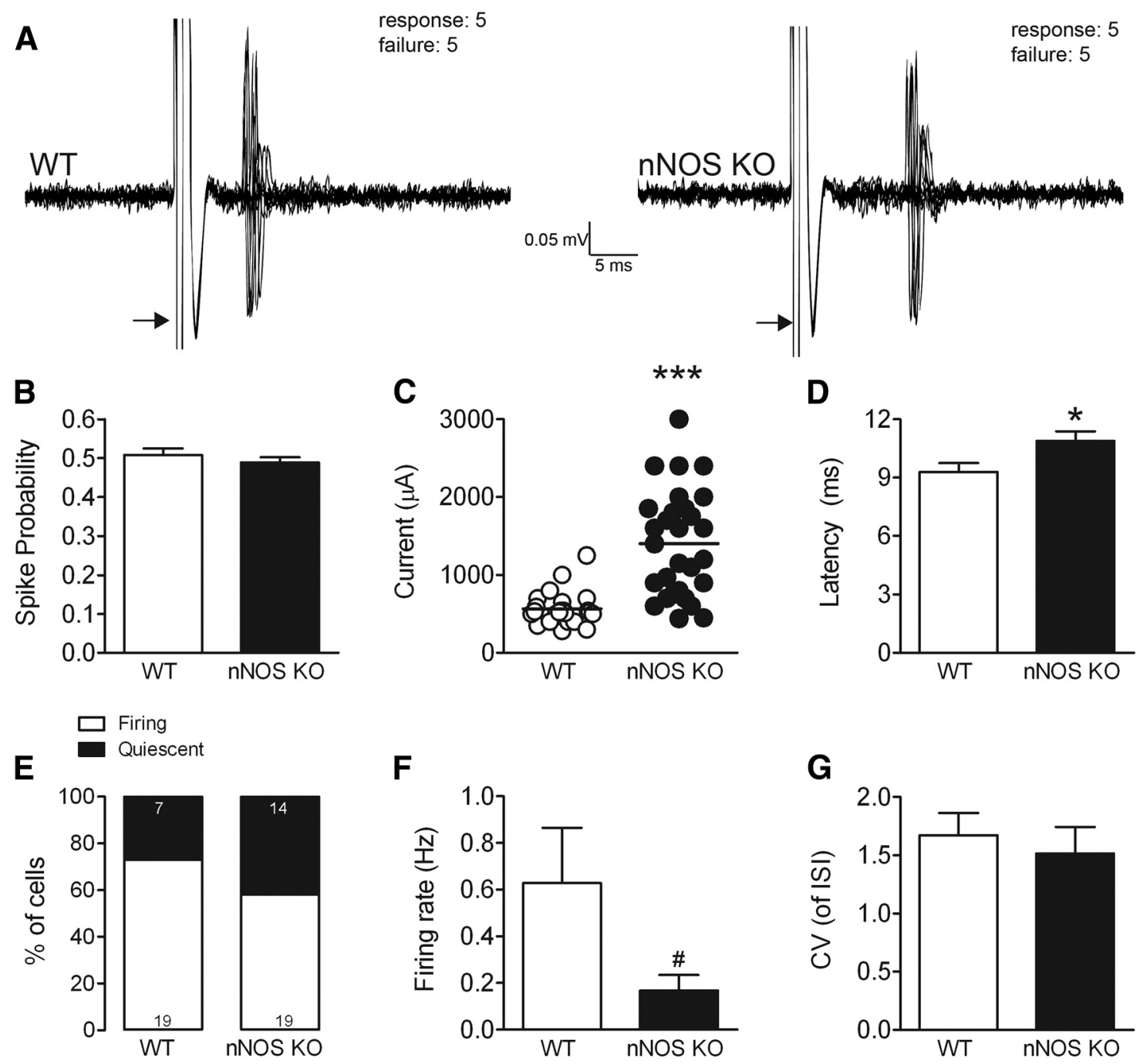

Figure 6. Genetic deletion of nNOS attenuates cortically evoked spike activity elicited by PDE10 inhibitor administration: between-subjects studies. $A$, Representative traces of cortically evoked spike activity of a single unit recorded in a WT (left) and nNOS KO (right) mouse after TP-10 administration. Ten superimposed traces of cortically evoked spike responses from a single striatal MSN are shown. Arrow indicates stimulus artifact. $\boldsymbol{B}$, Spike probability was titrated to $\sim 50 \%$ by the experimenter, and no differences in the probability of responses evoked by cortical stimulation were observed between WT and nNOS KO mice, indicating that currents were titrated accurately across groups ( $p>0.05 ; t$ test). C, Striatal MSNs recorded in nNOS KO mice in the presence of the PDE $10 \mathrm{~A}$ inhibitor exhibited decreased responsiveness to cortical stimulation compared with WT controls. Thus, an increase in the mean \pm SEM current intensity required to elicit spike activity $\sim 50 \%$ of the time was observed in nNOS KO mice. ${ }^{* * *} p<0.001$ ( $t$ test). $\boldsymbol{D}$, Striatal MSNs recorded in $n N O S$ KO mice in the presence of the PDE1OA inhibitor also exhibited an increase in the mean \pm SEM onset latency of cortically evoked spikes compared with WT controls. ${ }^{*} p<0.05$ ( $t$ test). $\boldsymbol{B}-\boldsymbol{D}$, Data are derived from $n=23$ WT and $n=29 \mathrm{nNOS} \mathrm{KO}$ MSNs (8 mice per group). $\boldsymbol{E}$, Percentage of cells that responded robustly to cortical stimulation that were firing or quiescent in the WT and nNOS mice (the number of cells for each condition is indicated within the percentage bars). There was no statistical difference in the population of spontaneously firing activity of cortically driven MSNs recorded in the striatum of WT and nNOS KO mice after TP-10 injection ( $p>0.05 ; \chi^{2}$ test). $F, A$ trend toward a decrease in the mean \pm SEM firing rate of MSNs recorded in the striatum of nNOS KO mice was observed after TP-10 injection compared with WT controls. $\# p=0.0827$ ( $t$ test). G, No difference in the mean \pm SEM coefficient of variance (CV) of the interspike interval (ISI) of spontaneously firing activity was observed between WT and nNOS K0 mice after TP-10 injection ( $p>0.05$; $t$ test).

activates the inhibitory phosphatase action of DARPP-32 and drives the dephosphorylation and inhibition of protein phosphatase-1, which can impact on the activity of numerous ion channels controlling membrane excitability.

\section{Implications for the treatment of neurological and psychiatric disorders}

The ability of PDE10A inhibitors to facilitate corticostriatal transmission is of considerable relevance for the treatment of a number of CNS disorders associated with disturbances in striatal function. Indeed, PDE inhibitors have recently attracted considerable interest as potential novel pharmacotherapies for the treatment of substance abuse (Logrip and Zorrilla, 2012), schizophrenia (Siuciak et al., 2006b; Schmidt et al., 2008; Grauer et al., 2009), Parkinson's disease (Sancesario et al., 2004; Giorgi et al., 2008; Calabresi et al., 2013), and Huntington's disease (HD) (Hebb and Robertson, 2007; Giampà et al., 2009, 2010; Kleiman et al., 2011). All of these disorders are associated with abnormal corticostriatal neurotransmission (Shepherd, 2013), a function strongly influenced by striatal cyclic nucleotide signaling (Greengard, 2001). Observations that striatal cAMP/cGMP levels are reduced in hyperdopaminergic states further suggest that PDE inhibitors may be beneficial for restoring cyclic nucleotide homeostasis in the pathologically impaired striatum (Kostowski et al., 1976; Siuciak et al., 2006a; Giorgi et al., 2008; Picconi et al., 2011). Given that DA transmission is thought to be increased in early $\mathrm{HD}$, it is plausible that overactive DA D2 receptor activation may reduce cyclic nucleotide tone and contribute to abnormali- 
ties in basal ganglia function and hyperactive movement observed in HD. Indeed, studies of HD knock-in mice have shown that steady-state levels of striatal cAMP are decreased in presymptomatic animals (Gines et al., 2003), a finding that is consistent with measures of CSF cAMP levels in HD patients (Cramer et al., 1984). In addition, although NOS-positive neurons are generally considered to be spared in $\mathrm{HD}$, there are reports of reduced nNOS mRNA in postmortem tissue from HD subjects (Norris et al., 1996) and in several mouse HD models (Deckel, 2001; PérezSeveriano et al., 2002). Given the above reports, it is plausible that selective PDE10A inhibitors and sGC activators will be useful therapeutic agents for facilitating corticostriatal transmission in pathophysiological conditions associated with basal ganglia dysfunction.

\section{References}

Bender AT, Beavo JA (2006) Cyclic nucleotide phosphodiesterases: molecular regulation to clinical use. Pharmacol Rev 58:488-520. CrossRef Medline

Calabresi P, Di Filippo M, Gallina A, Wang Y, Stankowski JN, Picconi B, Dawson VL, Dawson TM (2013) New synaptic and molecular targets for neuroprotection in Parkinson's disease. Mov Disord 28:51-60. CrossRef Medline

Cechova S, Pajewski TN (2004) The soluble guanylyl cyclase inhibitor ODQ, $1 \mathrm{H}$-[1,2,4] oxadiazolo[4,3-a]quinoxalin-1-one, dose-dependently reduces the threshold for isoflurane anesthesia in rats. Anesth Analg 99: 752-757. CrossRef Medline

Colwell CS, Levine MS (1995) Excitatory synaptic transmission in neostriatal neurons: regulation by cyclic AMP-dependent mechanisms. J Neurosci 15:1704-1713. Medline

Conti M, Beavo J (2007) Biochemistry and physiology of cyclic nucleotide phosphodiesterases: essential components in cyclic nucleotide signaling. Annu Rev Biochem 76:481-511. CrossRef Medline

Coskran TM, Morton D, Menniti FS, Adamowicz WO, Kleiman RJ, Ryan AM, Strick CA, Schmidt CJ, Stephenson DT (2006) Immunohistochemical localization of phosphodiesterase 10A in multiple mammalian species. J Histochem Cytochem 54:1205-1213. CrossRef Medline

Cramer H, Warter JM, Renaud B (1984) Analysis of neurotransmitter metabolites and adenosine $3^{\prime}, 5^{\prime}$-monophosphate in the CSF of patients with extrapyramidal motor disorders. Adv Neurol 40:431-435. Medline

Deckel AW (2001) Nitric oxide and nitric oxide synthase in Huntington's disease. J Neurosci Res 64:99-107. CrossRef Medline

Fujishige K, Kotera J, Omori K (1999) Striatum- and testis-specific phosphodiesterase PDE10A isolation and characterization of a rat PDE10A. Eur J Biochem 266:1118-1127. CrossRef Medline

Fujishige K, Kotera J, Yuasa K, Omori K (2000) The human phosphodiesterase PDE10A gene genomic organization and evolutionary relatedness with other PDEs containing GAF domains. Eur J Biochem 267:59435951. CrossRef Medline

Garthwaite J, Southam E, Boulton CL, Nielsen EB, Schmidt K, Mayer B (1995) Potent and selective inhibition of nitric oxide-sensitive guanylyl cyclase by $1 \mathrm{H}-[1,2,4]$ oxadiazolo[4,3-a] quinoxalin-1-one. Mol Pharmacol 48:184-188. Medline

Giampà C, Patassini S, Borreca A, Laurenti D, Marullo F, Bernardi G, Menniti FS, Fusco FR (2009) Phosphodiesterase 10 inhibition reduces striatal excitotoxicity in the quinolinic acid model of Huntington's disease. Neurobiol Dis 34:450-456. CrossRef Medline

Giampà C, Laurenti D, Anzilotti S, Bernardi G, Menniti FS, Fusco FR (2010) Inhibition of the striatal specific phosphodiesterase PDE10A ameliorates striatal and cortical pathology in R6/2 mouse model of Huntington's disease. PLoS One 5:e13417. CrossRef Medline

Gines S, Seong IS, Fossale E, Ivanova E, Trettel F, Gusella JF, Wheeler VC, Persichetti F, MacDonald ME (2003) Specific progressive cAMP reduction implicates energy deficit in presymptomatic Huntington's disease knock-in mice. Hum Mol Genet 12:497-508. CrossRef Medline

Giorgi M, D’Angelo V, Esposito Z, Nuccetelli V, Sorge R, Martorana A, Stefani A, Bernardi G, Sancesario G (2008) Lowered cAMP and cGMP signalling in the brain during levodopa-induced dyskinesias in hemiparkinsonian rats: new aspects in the pathogenetic mechanisms. Eur J Neurosci 28:941-950. CrossRef Medline
Grauer SM, Pulito VL, Navarra RL, Kelly MP, Kelley C, Graf R, Langen B, Logue S, Brennan J, Jiang L, Charych E, Egerland U, Liu F, Marquis KL, Malamas M, Hage T, Comery TA, Brandon NJ (2009) Phosphodiesterase $10 \mathrm{~A}$ inhibitor activity in preclinical models of the positive, cognitive, and negative symptoms of schizophrenia. J Pharmacol Exp Ther 331:574590. CrossRef Medline

Greengard P (2001) The neurobiology of slow synaptic transmission. Science 294:1024-1030. CrossRef Medline

Hebb AL, Robertson HA (2007) Role of phosphodiesterases in neurological and psychiatric disease. Curr Opin Pharmacol 7:86-92. CrossRef Medline

Hofer AM, Lefkimmiatis K (2007) Extracellular calcium and cAMP: second messengers as "third messengers?" Physiology (Bethesda) 22:320-327.

Kleiman RJ, Kimmel LH, Bove SE, Lanz TA, Harms JF, Romegialli A, Miller KS, Willis A, des Etages S, Kuhn M, Schmidt CJ (2011) Chronic suppression of phosphodiesterase 10A alters striatal expression of genes responsible for neurotransmitter synthesis, neurotransmission, and signaling pathways implicated in Huntington's disease. J Pharmacol Exp Ther 336: 64-76. CrossRef Medline

Kostowski W, Gajewska S, Bidzinski A, Hauptman M (1976) Papaverine, drug-induced stereotypy and catalepsy and biogenic amines in the brain of the rat. Pharmacol Biochem Behav 5:15-17. CrossRef Medline

Kraus MM, Prast H, Philippu A (2014) Influence of parafascicular thalamic input on neuronal activity within the nucleus accumbens is mediated by nitric oxide: an in vivo study. Life Sci 102:49-54. CrossRef Medline

Liu CN, Liu X, Gao D, Li S (2005) Effects of SNP, GLU and GABA on the neuronal activity of striatum nucleus in rats. Pharmacol Res 51:547-551. CrossRef Medline

Logrip ML, Zorrilla EP (2012) Stress history increases alcohol intake in relapse: relation to phosphodiesterase 10A. Addict Biol 17:920-933. CrossRef Medline

Loughney K, Snyder PB, Uher L, Rosman GJ, Ferguson K, Florio VA (1999) Isolation and characterization of PDE10A, a novel human $3^{\prime}, 5^{\prime}$-cyclic nucleotide phosphodiesterase. Gene 234:109-117. CrossRef Medline

Lugnier C (2006) Cyclic nucleotide phosphodiesterase (PDE) superfamily: a new target for the development of specific therapeutic agents. Pharmacol Ther 109:366-398. CrossRef Medline

Mallet N, Le Moine C, Charpier S, Gonon F (2005) Feedforward inhibition of projection neurons by fast-spiking GABA interneurons in the rat striatum in vivo. J Neurosci 25:3857-3869. CrossRef Medline

Menniti FS, Faraci WS, Schmidt CJ (2006) Phosphodiesterases in the CNS: targets for drug development. Nat Rev Drug Discov 5:660-670. CrossRef Medline

Nishi A, Watanabe Y, Higashi H, Tanaka M, Nairn AC, Greengard P (2005) Glutamate regulation of DARPP-32 phosphorylation in neostriatal neurons involves activation of multiple signaling cascades. Proc Natl Acad Sci U S A 102:1199-1204. CrossRef Medline

Norris PJ, Faull RL, Emson PC (1996) Neuronal nitric oxide synthase (nNOS) mRNA expression and NADPH-diaphorase staining in the frontal cortex, visual cortex and hippocampus of control and Alzheimer's disease brains. Brain Res Mol Brain Res 41:36-49. CrossRef Medline

Omori K, Kotera J (2007) Overview of PDEs and their regulation. Circ Res 100:309-327. CrossRef Medline

Ondracek JM, Dec A, Hoque KE, Lim SA, Rasouli G, Indorkar RP, Linardakis J, Klika B, Mukherji SJ, Burnazi M, Threlfell S, Sammut S, West AR (2008) Feed-forward excitation of striatal neuron activity by frontal cortical activation of nitric oxide signaling in vivo. Eur J Neurosci 27:1739_ 1754. CrossRef Medline

Paxinos G, Watson C (1998) The rat brain in stereotaxic coordinates. San Diego: Academic.

Paxinos G, Franklin, KBJ (2012) The mouse brain in stereotaxic coordinates. San Diego: Academic.

Pérez-Severiano F, Escalante B, Vergara P, Ríos C, Segovia J (2002) Agedependent changes in nitric oxide synthase activity and protein expression in striata of mice transgenic for the Huntington's disease mutation. Brain Res 951:36-42. CrossRef Medline

Picconi B, Bagetta V, Ghiglieri V, Paillè V, Di Filippo M, Pendolino V, Tozzi A, Giampà C, Fusco FR, Sgobio C, Calabresi P (2011) Inhibition of phosphodiesterases rescues striatal long-term depression and reduces levodopa-induced dyskinesia. Brain 134:375-387. CrossRef Medline

Sammut S, Threlfell S, West AR (2010) Nitric oxide-soluble guanylyl cyclase signaling regulates corticostriatal transmission and short-term synaptic 
plasticity of striatal projection neurons recorded in vivo. Neuropharmacology 58:624-631. CrossRef Medline

Sancesario G, Giorgi M, D’Angelo V, Modica A, Martorana A, Morello M, Bengtson CP, Bernardi G (2004) Down-regulation of nitrergic transmission in the rat striatum after chronic nigrostriatal deafferentation. Eur J Neurosci 20:989-1000. CrossRef Medline

Sano H, Nagai Y, Miyakawa T, Shigemoto R, Yokoi M (2008) Increased social interaction in mice deficient of the striatal medium spiny neuronspecific phosphodiesterase 10A2. J Neurochem 105:546-556. CrossRef Medline

Schmidt CJ, Chapin DS, Cianfrogna J, Corman ML, Hajos M, Harms JF, Hoffman WE, Lebel LA, McCarthy SA, Nelson FR, Proulx-LaFrance C, Majchrzak MJ, Ramirez AD, Schmidt K, Seymour PA, Siuciak JA, Tingley FD 3rd, Williams RD, Verhoest PR, Menniti FS (2008) Preclinical characterization of selective phosphodiesterase 10A inhibitors: a new therapeutic approach to the treatment of schizophrenia. J Pharmacol Exp Ther 325:681-690. CrossRef Medline

Seeger TF, Bartlett B, Coskran TM, Culp JS, James LC, Krull DL, Lanfear J, Ryan AM, Schmidt CJ, Strick CA, Varghese AH, Williams RD, Wylie PG, Menniti FS (2003) Immunohistochemical localization of PDE10A in the rat brain. Brain Res 985:113-126. CrossRef Medline

Sharott A, Doig NM, Mallet N, Magill PJ (2012) Relationships between the firing of identified striatal interneurons and spontaneous and driven cortical activities in vivo. J Neurosci 32:13221-13236. CrossRef Medline

Shepherd GM (2013) Corticostriatal connectivity and its role in disease. Nat Rev Neurosci 14:278-291. CrossRef Medline

Siuciak JA, Chapin DS, Harms JF, Lebel LA, McCarthy SA, Chambers L, Shrikhande A, Wong S, Menniti FS, Schmidt CJ (2006a) Inhibition of the striatum-enriched phosphodiesterase PDE10A: a novel approach to the treatment of psychosis. Neuropharmacology 51:386-396. CrossRef Medline

Siuciak JA, McCarthy SA, Chapin DS, Fujiwara RA, James LC, Williams RD, Stock JL, McNeish JD, Strick CA, Menniti FS, Schmidt CJ (2006b) Genetic deletion of the striatum-enriched phosphodiesterase PDE10A: evidence for altered striatal function. Neuropharmacology 51:374-385. CrossRef Medline

Soderling SH, Bayuga SJ, Beavo JA (1999) Isolation and characterization of a dual-substrate phosphodiesterase gene family: PDE10A. Proc Natl Acad Sci U S A 96:7071-7076. CrossRef Medline

Threlfell S, West AR (2013) Modulation of striatal neuron activity by cyclic nucleotide signaling and phosphodiesterase inhibition. Basal Ganglia 3:137-146. CrossRef Medline

Threlfell S, Sammut S, Menniti FS, Schmidt CJ, West AR (2009) Inhibition of phosphodiesterase $10 \mathrm{~A}$ increases the responsiveness of striatal projection neurons to cortical stimulation. J Pharmacol Exp Ther 328:785-795. CrossRef Medline

Tseng KY, Snyder-Keller A, O’Donnell P (2007) Dopaminergic modulation of striatal plateau depolarizations in corticostriatal organotypic cocultures. Psychopharmacology (Berl) 191:627-640. CrossRef Medline

Tseng KY, Caballero A, Dec A, Cass DK, Simak N, Sunu E, Park MJ, Blume SR, Sammut S, Park DJ, West AR (2011) Inhibition of striatal soluble guanylyl cyclase-cGMP signaling reverses basal ganglia dysfunction and akinesia in experimental parkinsonism. PLoS One 6:e27187. CrossRef Medline

West AR (2010) Nitric oxide signaling in the striatum. In: Handbook of basal ganglia structure and function. San Diego: Academic/Elsevier.

West AR, Galloway MP (1997) Endogenous nitric oxide facilitates striatal dopamine and glutamate efflux in vivo: role of ionotropic glutamate receptor-dependent mechanisms. Neuropharmacology 36:1571-1581. CrossRef Medline

West AR, Grace AA (2004) The nitric oxide-guanylyl cyclase signaling pathway modulates membrane activity states and electrophysiological properties of striatal medium spiny neurons recorded in vivo. J Neurosci 24: 1924-1935. CrossRef Medline

West AR, Tseng KY (2011) Nitric oxide-soluble guanylyl cyclase-cyclic GMP signaling in the striatum: new targets for the treatment of Parkinson's disease? Front Syst Neurosci 5:55. CrossRef Medline

West AR, Galloway MP, Grace AA (2002) Regulation of striatal dopamine neurotransmission by nitric oxide: effector pathways and signaling mechanisms. Synapse 44:227-245. CrossRef Medline

Xie M, Rich TC, Scheitrum C, Conti M, Richter W (2011) Inactivation of multidrug resistance proteins disrupts both cellular extrusion and intracellular degradation of cAMP. Mol Pharmacol 80:281-293. CrossRef Medline 